\title{
Health care and social service professionals' perceptions of a home-visit program for young, first-time mothers
}

\section{S.-A. Li, MSc (1, 2); S. M. Jack, PhD (1, 2, 3); A. Gonzalez, PhD (2, 4); E. Duku, PhD (2, 4); H. L. MacMillan, MD (1, 2, 4, 5)}

This article has been peer reviewed.

\section{Abstract}

Introduction: Little is known about health care and social service professionals' perspective on the acceptability of long-term home-visit programs serving low-income, first-time mothers. This study describes the experiences and perspectives of these community care providers involved with program referrals or service delivery to mothers who participated in the Nurse-Family Partnership (NFP), a targeted nurse home-visit program.

Methods: The study included two phases. Phase I was a secondary qualitative data analysis used to analyze a purposeful sample of 24 individual interviews of community care providers. This was part of a larger case study examining adaptations required to increase acceptability of the NFP in Hamilton, Ontario, Canada. In Phase II ( $=4)$, themes identified from Phase I were further explored through individual, semi-structured interviews with community health care and social service providers, giving qualitative description.

Results: Overall, the NFP was viewed as addressing an important service gap for firsttime mothers. Providers suggested that frequent communication between the NFP and community agencies serving these mothers could help improve the referral process, avoid service duplication, and streamline the flow of service access. The findings can help determine key components required to enhance the success of integrating a homevisit program into an existing network of community services.

Conclusion: The function of home-visit programs should not be viewed in isolation. Rather, their potential can be maximized when they collaborate and share information with other agencies to provide better services for first-time mothers.

Keywords: home visits, early intervention, parent education, mothers, Nurse-Family Partnership, community professionals

\section{Introduction}

Pregnant women with limited financial, psychological and personal resources are at high risk for adverse pregnancy outcomes, including preterm birth or low birth-weight babies. ${ }^{1,2}$ Prenatal and early childhood home visits facilitate access to and use of community health and social services by vulnerable pregnant women and families with young children. ${ }^{3,4}$ In Canada, it is common practice to offer universal (nontargeted) home visits to new and expectant parents and then more intensive home visits to specific target populations, typically families with children at risk of poor health or social or emotional development. ${ }^{5}$

The Nurse-Family Partnership (NFP) is an evidence-based intervention that was developed based on theories of human ecology, ${ }^{6}$ self-efficacy ${ }^{7}$ and human attachment. ${ }^{8}$ Over
Key findings

- Community care providers recognized the added value of the Nurse-Family Partnership (NFP) program to existing community services.

- These health care and social service providers also preferred greater collaboration and more frequent communication with NFP to form an integrated network of services for at-risk young mothers, promoting seamless access to community services.

the past 35 years, the NFP has been extensively evaluated in a series of three randomized controlled trials (RCTs). ${ }^{9-11}$ Once the effectiveness of the intervention in improving pregnancy outcomes as well as maternal and child health and psychosocial well-being was established, the program began to be fully implemented. Currently, eligible families in 43 states plus the United States Virgin Islands are enrolled in the NFP. ${ }^{11-13}$

The NFP developed 18 model elements as a guide for implementing agencies. These model elements ensure that outcomes would be comparable to those measured in the three evaluating RCTs on which the current approach to scaling up the program is based. ${ }^{14}$ Two of the elements specifically refer to the importance of partnerships with other organizations, community support and recognition, and the level of community involvement required to successfully implement programs. ${ }^{15}$ Establishing alliances between community stakeholders and organizations

Author references:

1. Department of Clinical Epidemiology \& Biostatistics, McMaster University, Hamilton, Ontario, Canada

2. Offord Centre for Child Studies, McMaster University, Hamilton, Ontario, Canada

3. School of Nursing, McMaster University, Hamilton, Ontario, Canada

4. Department of Psychiatry and Behavioural Neurosciences, McMaster University, Hamilton, Ontario, Canada

5. Department of Pediatrics, McMaster University, Hamilton, Ontario, Canada

Correspondence: Shelly-Anne Li, Offord Centre for Child Studies, 1280 Main Street West, Hamilton, ON L8S 4K1; Tel: 416-662-2232; Email: shellyanne.li@gmail.com 
from multiple sectors to promote and sustain community health has become an important strategy for meeting community health needs. ${ }^{16}$ Home visitors form strong partnerships with other health care and social service professionals (e.g. primary care physicians, pediatricians and social workers), who are providing vital support and essential education to high-risk families within the same community. ${ }^{17-19}$ These strong partnerships are thought to improve families' adherence to medical prevention and treatment regimens. ${ }^{20}$ Given that local community support is a key element in determining the success of the implementation of the program, it is crucial to understand the perspective of the health care professionals who form the broader support network system in which the NFP is situated.

The NFP has been evaluated in Canada in Hamilton, Ontario, ${ }^{21,22}$ and an RCT is currently assessing its effectiveness in British Columbia. In-depth investigations suggest that public health nurses (PHNs) in Canada, as well as the clients receiving the intervention and their families, consider NFP model elements and home visits acceptable. ${ }^{21-24}$ However, the perspective of health care and social service professionals who provide the NFP have not been explored. Our study addressed this gap by examining the factors that influence the acceptability of home visitation programs among health care and social service professionals. It takes into account the points of view of professionals who can help inform health administrators about the readiness of the community for an evidence-based home visitation within the Canadian health care system.

\section{Methods}

This qualitative study included two distinct phases. Phase I was a secondary analysis of data from a qualitative case study ${ }^{21}$ that explored the acceptability of the NFP among young low-income, first-time mothers and their families, PHNs, and community stakeholders, including health care and social service professionals, in Hamilton, Ontario. Because the data used for the secondary data analysis were based on questions posed by investigators in the primary study, the responses may not adequately reflect the research questions from this study. ${ }^{25}$ To overcome this limitation, Phase II consisted of additional individual semi-structured interviews with community professionals. These interviews serve as a follow-up to elaborate and confirm Phase I findings. Also, as data from Phase I were collected in 2009, Phase II was undertaken to provide some preliminary indication of whether the findings were still valid in 2014.

\section{Sampling}

In Phase I, we included for analysis a subset $(\mathrm{n}=24)$ of the individual interviews of community stakeholders (who included health care and social service professionals). Table 1 shows further demographic characteristics of the sample.

We purposefully sampled Phase II participants to select those who could provide information-rich responses to our research questions. The sample included (1) Children's Aid Society (CAS) professionals who could provide insight into the role of the NFP in the context of child protection services, and (2) Hamilton Public Health
Services (HPHS) professionals who could provide in-depth information about the NFP home-visit program in Hamilton. Based on the findings from Phase I, many community care providers were aware of the NFP's influence on the number of CAS referrals received and the timing of closing cases. Professionals were not eligible for participation if they did not have first-hand knowledge of the implementation of the NFP in Hamilton.

We approached 10 social service and health care professionals (3 from HPHS; 7 from CAS) who were considered to have first-hand knowledge of the NFP. Of the 8 participants in the primary study, 4 responded to the invitation email sent by the principal investigator and 3 participated; 2 other individuals were identified through snowball sampling* and invited to participate in our study, and 1 consented. Altogether, 4 social service and health care professionals agreed to participate in this study.

\section{Participants}

The 4 participants ( 3 women and 1 man) had been involved with the NFP since its

\section{TABLE 1}

\section{Characteristics of the Phase I sample}

\begin{tabular}{lc}
\hline Occupation & $\mathbf{n}(\%)$ \\
\hline Frontline care providers (team leaders, support workers) & $5(20.8)$ \\
Health care professionals (medical doctors, registered nurses) & $3(12.5)$ \\
Social service providers (social workers, school liaisons) & $6(25.0)$ \\
Decision makers (directors, supervisors, managers) & $6(25.0)$ \\
Child protection professionals & $3(12.5)$ \\
NFP administrative staff & $1(4.2)$ \\
\hline Professional designation & $\mathbf{n}(\%)$ \\
\hline Registered social worker & $17(70.8)$ \\
Medical doctor & $2(8.3)$ \\
Registered nurse & $2(8.3)$ \\
Other diploma & $2(8.3)$ \\
Not provided & $1(4.2)$ \\
\hline Other demographics & Mean (SD) \\
\hline Age, years & $51.8(5.3)$ \\
Number of years in profession & $18.1(0.5)$ \\
Number of years in current position & $7.8(5.5)$ \\
Number of low-income pregnant women interacted within last year & $96.6(172.5)$ \\
\hline
\end{tabular}

Abbreviations: NFP, Nurse-Family Partnership; SD, standard deviation. can take part in it. 
implementation in Hamilton and so were able to provide rich, contextual information. The participants had worked at their respective agency ( 3 from CAS and 1 from HPHS) for a mean (standard deviation) of 19 (6) years and in their current role for a mean of 12 (4) years. Participants had either a Bachelor of Social Work $(\mathrm{n}=2)$ or a Master of Social Work $(n=2)$.

\section{Data collection}

We obtained written informed consent prior to each interview. Data were collected using individual, semi-structured, digitally recorded interviews that lasted approximately $60 \mathrm{~min}$ utes. To gain a deeper appreciation and understanding of the experiences and perspectives of the community professionals, the interview guide was developed from (but not limited to) the themes identified in Phase I (see Table 2; interview guides available from the authors on request). Data analysis and collection occurred concurrently and questions were modified in the interview guide to allow for better capture of themes.

\section{Data management}

Once transcribed, we de-identified the interviews and imported them into NVivo 10 (QSR International Pty Ltd; Doncaster, VC). ${ }^{26}$ The use of NVivo also allowed the research process to be carefully tracked, which enhanced the auditability and credibility of the findings.

\section{Data analysis}

To the best of our knowledge, no previous studies had explored the factors that influence the acceptability of an early intervention program among health care and social service providers. We used inductive, conventional content analysis on the qualitative data from Phases I and II, and named the emergent codes based on the information shared by the study participants; we did not impose preconceived categories or theoretical perspectives on the data. We grounded the participants' unique perspectives, as generated by this conventional approach, in actual data. $^{27}$

In Phase I, data analysis began with open coding, which involved highlighting the words in the transcript that captured participants' salient thoughts about the acceptability of the NFP home-visit program. Next, codes (essentially, labels assigned to segments of text to provide meaning) emerged. We constructed a list of preliminary codes by open coding 5 transcripts, and then developed a codebook as a guide for coding the subsequent interviews. This codebook was revisited and refined as new codes and concepts emerged from coding subsequent transcripts. Some categories were combined and others split into subcategories based on how different codes were related and linked. Themes emerged from the underlying meaning of the categories.

We followed similar methods for analyzing Phase II data. Specifically, we used the codes developed from Phase I to begin the analysis for Phase II and expanded the codebook as new codes and concepts emerged.

We applied the four strategies recommended by Lincoln and Guba ${ }^{28}$ —credibility, transferability, dependability and confirmability-to ensure study rigour. We achieved credibility through peer debriefing and member checking. A second coder (MT) coded a subset of transcripts (four from Phase I and one from Phase II) and we compared these codes with those of the primary coder to achieve dependability. To obtain transferability, we described the research context and participant characteristics in detail. Maintaining an audit trail and field notes achieved confirmability was through.

The Hamilton Integrated Research Ethics Board approved the study.

\section{Results}

Phase I consisted of a secondary analysis of the individual interviews conducted with community health care and social service providers. We identified three main themes in Phase I: (1) the NFP as an evidence-based, structured education program for first-time mothers; (2) the NFP in partnership with other community agencies; and (3) the NFP in a community context (Table 2 ).

We continued to explore these themes in Phase II through interviews with HPHS and local CAS agency professionals with a significant amount of experience and knowledge of collaborating with NFP PHNs, supervisors and clients.

\section{The NFP as an evidence-based, structured education program for first-time mothers}

The health care and social service providers we interviewed saw the NFP as filling
TABLE 2

Phase I themes, categories and codes

\begin{tabular}{|c|c|c|}
\hline Theme & Category & Codes \\
\hline \multirow[t]{2}{*}{$\begin{array}{l}\text { NFP as an evidence-based, structured } \\
\text { education program for first-time mothers }\end{array}$} & NFP elements & $\begin{array}{l}\text { Program structure and intensity } \\
\text { NFP as an evidence-based } \\
\text { intervention } \\
\text { Preparing clients for motherhood }\end{array}$ \\
\hline & Role of PHNs & $\begin{array}{l}\text { PHN-client relationship as crucial } \\
\text { aspect of NFP } \\
\text { PHNs' expertise and professional } \\
\text { image }\end{array}$ \\
\hline \multirow[t]{2}{*}{$\begin{array}{l}\text { NFP in partnership with other community } \\
\text { agencies }\end{array}$} & & $\begin{array}{l}\text { PHNs as a direct connection to } \\
\text { community services for clients } \\
\text { Integral role of community support } \\
\text { for NFP to continue and thrive }\end{array}$ \\
\hline & $\begin{array}{l}\text { Collaboration between } \\
\text { agencies and NFP }\end{array}$ & $\begin{array}{l}\text { Preference for further collaboration } \\
\text { with NFP } \\
\text { Preference for constant } \\
\text { communication with NFP PHNs }\end{array}$ \\
\hline NFP in a community context & Impact of NFP & $\begin{array}{l}\text { Serving and supporting a needs gap } \\
\text { Issue with duplication of services } \\
\text { with existing community services } \\
\text { Child protection services }\end{array}$ \\
\hline
\end{tabular}

Abbreviations: NFP, Nurse-Family Partnership; PHN, public health nurse. 
an important gap in service for lowincome, first-time mothers in Hamilton, Ontario. The interviewees unanimously expressed appreciation for the program's structure, its intensity in preparing clients for motherhood, its strong foundation of evidence, the expertise that PHNs brought to the home-visit program, and the close relationship built between each client and her PHN.

\section{NFP elements}

The interviewees noted the following unique aspects of the NFP: home visits start early in pregnancy; nurses visit frequently; and families remain enrolled in the program until the child's second birthday. Further, the interviewees considered the clear, defined goals for each visit, as laid out in the structured guidelines, a key strength and a unique characteristic of the NFP compared with other home-visit programs in the community. During each home visit, PHNs discuss topics related to six core content domains: personal health, environmental health, maternal role, life course development, family and friends, and health and human services. The interviewees also noted the program's tendency to encourage positive parent-child relationships and support the development of strong parenting skills while achieving the optimal balance in program intensity and frequency of scheduled home visits. One of the frontline care providers in a maternity home commented:

My favourite part of it is how intense it is and how it starts early in the pregnancy. You know I think it gets expectant mothers starting to think about parenting and all that kind of stuff ... And I also like that after the birth of the baby they visit once a week for 6 weeks ... because that's ... sort of a high-risk time, so I think that's a good component-and the fact that it goes for 2 years too ... So it's very intense, I guess. (S523)

Agency leaders and frontline care providers were also positive about the strength of the outcomes associated with client participation in the NFP. They acknowledged that this participation is an important evidence-based intervention. Overall, participants were aware of the evidence from the United States, including the results from the NFP replications. A CAS professional said:
As far as this particular program goes, I've been pretty impressed ... obviously the results that they've seen in the US in terms of long-term impact and outcomes ... that was very impressive to look at. (S509)

The participants in this study described the NFP as very beneficial to low-income, first-time mothers. By establishing the relationship with the client before the baby is born, PHNs were considered to be in the optimum position to address the risk factors known to influence prenatal and infant health outcomes and to support the client in preparing for her new role as a parent. One of the frontline care providers reflected on the benefits of the educational components:

Oh, the educational factor and the hands-on educational factors are really an enormous help to the girls ... that is really important that somebody be there to help with those types of things ... giving them ... a chance to talk about some of the stresses that they're having in their life with regard to parenting or taking care of their child. (S521)

This also illustrates a core component of the NFP-the formation of a therapeutic relationship between the client and her PHN, particularly when a PHN becomes a client's go-to person for talking about stressors in her life. In addition to educating clients about health issues and teaching positive parenting skills, PHNs play a key role in empowering clients by boosting their confidence and self-esteem and by introducing positive, productive activities in their life.

\section{The role of PHNs}

Participants saw the regular one-on-one interactions between the PHN and the client as essential to establishing a trusting, longterm relationship, one that could last up to 2.5 years. As one social worker elaborated:

I think it's definitely somebody that they can feel confident in calling whenever they have a question or a concern ... it's my understanding that the clients have their [PHNs'] cell phone numbers. You don't get that very often that you can just pick up the phone and just get a hold of somebody who's in the medical field right away ... I think young mothers need to have somebody who they can feel confident and trust in that way. (S511)

The participants all agreed that PHNs brought specific knowledge and expertise on health issues to the clients in the NFP. They perceived PHNs as having a good reputation and a more positive image than that of other community professionals who work with young, low-income mothers, including social workers, CAS workers or parent support workers. One social worker contrasted the public images of PHNs versus that of social workers and CAS professionals:

I think that you know people often get their anxieties heightened when they know ... if they know it's a social worker. I can often sell a program easier if I say it's voluntary, it's a nurse who visits all walks of life, it's not somebody who's coming to "check up on you." Whereas people feel that if it's a Children's Aid worker or parent support worker that that's kinda more the case. (S511)

\section{The NFP in partnership with other community agencies}

PHN as a direct connection to community services for clients

The community care providers perceived PHNs as a direct connection to those community services that offer support to young, low-income mothers. These include supports for housing, schooling or health care. Care providers emphasized the importance for programs to be collaborative and pointed out the value of a bidirectional approach to promoting community services.

The participants also described the integral role of community support for the NFP to continue and thrive. One of the social service providers suggested that the NFP needs to be part of a continuum of support for high-risk mothers as their problems with housing and employment as well as any mental health issues may not have entirely resolved upon 
graduation from the NFP. As such, the NFP is in a position to prepare the other agencies that would continue or begin to provide support to these young mothers. This suggests that further collaboration between the NFP and other community agencies to form a concrete, supportive infrastructure for this targeted population is in order. One of the community care providers discussed collaboration as a means to prevent duplication of services for the clients. She described:

So it's just a matter of connecting and, you know, collaborating so that you're not duplicating. And I think that's what's really important and that's what I try to do when, when I ... when there was a number of different agencies, specifically if there's a Nurse-Family Partnership ... let's pull everyone together .... (S519)

\section{Preference for constant communication with} NFP PHNs

The care providers emphasized the potential benefits of more communication with NFP PHNs, including better referrals and the capacity for enhanced community support for the NFP, as well as greater awareness of the goals that the NFP is trying to achieve. One of the community care providers suggested that planning meetings with the NFP would help them keep up-to-date with the NFP's progress within the community, which could, in turn, help their agency support the NFP more effectively, particularly around referrals:

I think meetings every once in a while to keep us up-to-date, to let us know what's happening so that we can support the program. So that ... it's you know the ... what happens is if you know what something is you can refer it a whole lot better. (S503)

\section{The NFP in a community context}

The NFP was thought to positively impact the community agencies without interfering with the logistics of existing services. The community care providers felt that the NFP filled a gap for first-time disadvantaged young mothers in Hamilton. Many of the providers also commented on the impact the NFP had on child protection services, for example, closing CAS cases earlier, reducing the number of CAS files being opened and enhancing the process of safety planning with high-risk families. Some providers raised concerns about duplicating services with existing agencies, and some compared the HPHC with the NFP.

\section{Impact of NFP on existing services within} community

When participants were asked how the NFP affected their existing services, all of them reported that the NFP did not interfere with the logistics of how they provide their services; rather, the NFP augmented the services they provided to first-time mothers. They acknowledged the positive impact of PHNs on their services, both directly and indirectly (through the clients). As one physician related:

Yeah, I was very excited about it and, from my perspective as a family doc, it saves me time and I know that I can hook up my patient with resources that hopefully will be able to help her keep a baby and be a better mother ... The reality is no family doc, no matter how much they care about their patients, has the time to do what the nurses are doing-I'll be perfectly honest. (S514)

Impact of the NFP on child protection services

Many of the participants commented on the impact that the NFP had on child protection services (specifically CAS). This aspect warrants a separate description of findings from other existing community services. CAS workers reported feeling more confident when another health care professional was also working closely with their clients. CAS workers also commented that they trusted that PHNs would communicate any concerns with the client to the CAS. Another participant considered NFP as "more intense work" and felt "more confident closing the [CAS] file" when the PHN was visiting the client regularly. This participant further elaborated:

I don't know how this particular case would have went [sic] if I didn't have that other person [the PHN] to help facilitate the meetings that we had, to help be another person that was having eyes on the situation, and also in terms of giving me the information [about what] was actually what was going on, right? So I think definitely it helped to just give me a clearer picture and to make my planning easier, and to provide a better situation and plan for the baby and for the mother. (S515)

CAS professionals valued working with NFP PHNs for a common client, and often described their positive experiences and the helpful support they received from the PHNs. Some barriers to a seamless collaboration did exist, however. One CAS professional recounted her experience with a PHN when they worked "side by side together.' She elaborated on the challenges of understanding each other's roles; specifically, when her role as a CAS worker changed after a child was found in need of protection (according to the Ontario Child and Family Services $\mathrm{Act}^{29}$ ) and the CAS had to intervene and implement specific services for the client:

There was a couple of times, I have to be honest, where it was ... I didn't know if it was because she didn't understand our role and maybe I didn't understand her role as much as we needed to, to work more together ... when the baby is born and it becomes a protection file ... there's then child safety and protection concerns. So our role changes. So when I worked with the (NFP PHN) with this mother before the baby was born, it was a lot different and easier as far as following her ... But once it became protection I had to intervene. I had to put services that the Society has in place for this mother because it became protection and there were concerns ... (S516)

\section{Synthesis of results}

Integrating the results from the first and second phases of this study gave us the opportunity to further explore findings that emerged from the secondary data analysis and to answer some of the remaining questions. Findings from the second phase of the study (which reflected current perceptions on NFP delivery) were largely consistent with those from the first (perspectives dated back to 2009; Table 3 summarizes the 
TABLE 3

Summary of findings consistent in both Phases I and II interviews

\begin{tabular}{|c|c|}
\hline Theme & Summary \\
\hline $\begin{array}{l}\text { NFP as an evidence-based, structured education } \\
\text { program for first-time mothers }\end{array}$ & $\begin{array}{l}\text { Participants described the positive feedback from clients about the NFP. Young mothers appear to be very } \\
\text { satisfied with the program's deliverables. } \\
\text { The idea of establishing a long-term relationship with family is still viewed as the main component of the NFP. } \\
\text { Participants spoke about the benefits that the NFP gives to the mother and child. } \\
\text { The need for interpretation services to better screen young mothers still exists. }\end{array}$ \\
\hline NFP in partnership with other community agencies & $\begin{array}{l}\text { Participants suggested more communication and how to frequently share information (e.g., inviting PHNs to } \\
\text { visit the agencies to educate staff on first-time, young mothers and their experiences with them, or provide } \\
\text { quick updates via phone). }\end{array}$ \\
\hline NFP's relationship with community agencies & $\begin{array}{l}\text { PHNs are considered an important resource for connecting their clients to community services. } \\
\text { NFP involvement gives CAS workers confidence in closing cases. } \\
\text { PHNs play an integral role in the development of the safety plan with CAS workers and family. }\end{array}$ \\
\hline
\end{tabular}

Abbreviations: NFP, Nurse-Family Partnership; PHN, public health nurse.

major findings that were consistent between the two phases). Nonetheless, data from Phase II added to the information on the current status of NFP, particularly to those areas that needed further exploration, and told us about the current challenges faced by the NFP (see Table 4).

\section{Discussion}

The results provide valuable insights into the acceptability of the NFP in a Canadian community. These perspectives from community health and social care providers confirm and support the experiences of young, disadvantaged first-time mothers who participated in the NFP in Hamilton, Ontario. $^{28}$ Specifically, mothers in the program considered the PHNs as credible health experts as well as supportive friends whom they could trust and confide in. In addition, mothers in the case study recognized the empowering relationship they had with the PHNs and considered them advocates when dealing with community agencies.

After almost six years of working with the NFP in Hamilton, CAS professionals and PHNs appear to have adopted several of the strategies suggested by care providers in Phase I to promote interorganizational collaboration. These strategies include (1) outlining the responsibilities of the CAS worker and the PHN at the start of the working relationship; (2) clearly delineating and communicating each professional's goals to do with working with the family; and (3) organizing meetings with the family to discuss ways to enhance their support. Interorganizational collaboration is considered one of the strategies that prevent duplication in services. ${ }^{31}$

In Phase I, community care providers also expressed the view that it was initially challenging to differentiate between existing maternity home services and the NFP. After working with NFP PHNs, the providers came to appreciate the NFP approach, which focusses its child developmentbased foundation on young, disadvantaged, first-time mothers. In Phase II, it was revealed that the NFP team members have put significant effort in helping community partners understand the NFP recommendations and goals by holding meetings with decision makers at the provincial level and with other community stakeholders. The NFP also promoted collaboration with other organizations by forming interorganizational alliances, for example, through coordinating councils or community advisory boards where leaders and/or direct care providers can set common goals. ${ }^{32}$ Establishing a community advisory board is one of the 18 core

TABLE 4

New findings and concepts from Phase II

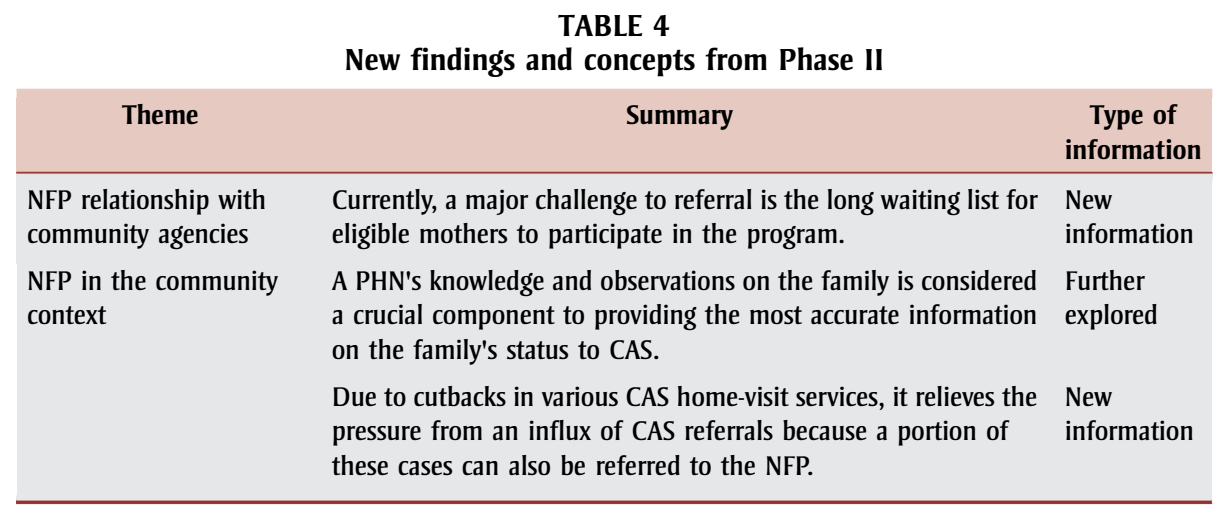

Abbreviations: NFP, Nurse-Family Partnership; PHN, public health nurse. model elements of the NFP that agencies agree to implement as part of their contract with the program. ${ }^{14}$

Our findings revealed that the NFP, a longanticipated, effective intervention targeting high-risk, first-time mothers in Hamilton, is recognized as filling an important gap in service. Health care and social service professionals in this study saw partnership as the key to the NFP's success and sustainability in the community. This finding is in line with reviews that report more robust outcomes when home-visit programs partner with other early intervention services and community support programs. ${ }^{17}$ Disadvantaged families accessing early childhood services often have complex needs that cannot be adequately addressed by a single service such as home visiting and, as such, community services need to work together to target these unmet needs. ${ }^{20}$

The health care and social service professionals we interviewed in this study also pointed out how crucial it is to continue to provide support for clients after they 
graduate from the NFP so that they reach their full potential as parents. This finding is supported by a brief report on the Family-Nurse Partnership in Scotland. ${ }^{33}$

\section{Study strengths and limitations}

Our study had several strengths. We used multiple strategies, such as member checking, double coding and use of an audit trail, to ensure methodological rigour. Further, the Phase I sample size ( $n=24$ ) allowed for saturation and for themes to emerge. The implementation of a two-phase study design addressed the inherent challenges of secondary data analyses: 1) the re-analysis of data, which may not adequately reflect the new research questions; and 2) data from the original study may be bound by time and scope. $^{25}$ The categories and themes derived from the first phase (secondary analysis of individual interviews) served as a guide for developing interview questions for the second phase of the study.

There were also some important limitations, particularly with regard to sampling for Phase II. The sample for this phase was extremely small $(n=4)$, and saturation for additional themes could not be reached with the new data. Although it is not possible to reach any firm conclusions because of the very limited sample size in Phase II, we did identify some unique concepts that warrant further exploration. Expanding the number of clients interviewed in Phase II to include more health care and social service providers who are connected with the NFP would have enhanced the transferability of findings from this study. Triangulation, which involves using different methods or data sources for data collection and/or analysis, for example, through focus groups or other data sources such as newsletters or meeting minutes, ${ }^{28}$ would also have been useful.

\section{Future research considerations}

Nurse home visits have been a critical component of public health for over a century. Although much is known about the importance of the therapeutic relationship between the nurse, the client and her family, no studies to date have examined the relationship between nurse home visitors and community care providers. Our findings suggest that closer exploration of the role of social service and health care providers within the context of home visitation is important in understanding approaches to service provision and implementation.

\section{Implications}

The data collected through individual interviews provides insight into the key components required to enhance the success of integrating a long-term home-visit program into an existing network of community services. Such findings are important considerations in examining the effectiveness of the intervention. Currently, an RCT is underway in British Columbia as the next phase of NFP implementation in Canada. Our study has identified the need to establish stronger collaborations with community agencies, and to consider how their specific roles overlap.

\section{Conclusion}

Health care and social service providers recognized the added value of the NFP to existing community services for disadvantaged first-time mothers. PHNs who delivered the NFP intervention were seen as playing a key part in connecting these mothers to community services, preparing them for motherhood, and preventing or ending the involvement of child protection services. Care providers also looked to collaborating with the NFP to form an integrated network of services that make transitions between services as seamless as possible.

This is the first qualitative study to explore the acceptability of a long-term home-visit program from the perspective of health care and social service providers within a community. It would be useful to examine the perceptions of care providers about the ongoing implementation of the NFP and the extent to which it is seen as meeting the needs of the community.

\section{Acknowledgments}

Funding for the original research was received from the Nursing Research Fund, Ontario Ministry of Health and Long-Term Care and from the Provincial Centre of Excellence for Child and Youth Mental
Health at the Children's Hospital of Eastern Ontario. We are grateful to the community care providers who participated in the original study (Phase I) and those who were interviewed for this study (Phase II). Dr. Harriet MacMillan is supported by the Chedoke Health Chair in Child Psychiatry. Special thanks to Dr. Masako Tanaka for her role as second coder to help achieve intercoder agreement.

\section{References}

1. McCormick MC, Brooks-Gunn J, Shorter T, Holmes JH, Wallace CY, Heagerty MC. Factors associated with smoking in lowincome pregnant women in relationship to birth-weight, stressful life events, social support, health behaviors and mental distress. J Clin Epidemiol. 1990;43(5):441-8.

2. Sable MR, Wilkinson DS. Impact of perceived stress, major life events and pregnancy attitudes on low birth weight. Fam Plann Perspect. 2000;32:288-94.

3. Issel LM, Forrestal SG, Slaughter J, Wiencrot A, Handler A. A review of prenatal home-visiting effectiveness for improving birth outcomes. J Obstet Gynecol Neonatal Nurs. 2001;40(2):157-65.

4. Gomby DS, Larson CS, Lewit EM, Berman RE. Home visiting: analysis and recommendations. Future Child. 1993;3(3):6-22.

5. Gates R, Nickel D, Muhajarine N. Evaluation Research Team. The effectiveness of home visitation interventions similar to KidsFirst, Saskatchewan: a focused literature review [Internet]. Saskatoon (SK): Early Learning and Child Care Branch, Saskatchewan Ministry of Education; 2010 [cited 2014 June 23]. Available from: http:// kidskan.ca/wp-content/uploads/2013/05/ 3a-Home-Visiting-Lit-Review-KidsFirst-Evaluation-2009.pdf

6. Bronfenbrenner U. Ecology of human development: experiments by nature and design. Cambridge (MA): Harvard University Press; 1979.

7. Bandura A. Self-efficacy: toward a unifying theory of behavioral change. Psychol Rev. 1977;84(2):191-215.

8. Bowlby J. Attachment and loss: Attachment. London (UK): Hogarth Press and the Institute of Psycho-Analysis; 1969. 
9. Olds DL, Eckenrode J, Henderson CR, et al. Long-term effects of home visitation on maternal life course and child abuse and neglect. Fifteen-year follow-up of a randomized trial. JAMA. 1997;278(8):637-43.

10. Olds D, Robinson J, Pettit L, et al. Effects of home visits by paraprofessionals and by nurses: age 4 follow-up results of a randomized trial. Pediatrics. 2004;114(6) 1560-8.

11. Olds DL, Kitzman H, Cole RE, Hanks CA, Arcoleo KJ, Anson EA, et al. Enduring effects of prenatal and infancy home visiting by nurses on maternal life course and government spending: follow-up of a randomized trial among children at age 12 years. Arch Pediatr Adolesc Med. 2010;164(5): 419-24.

12. Gomby DS. Home visitation in 2005: outcomes for children and parents. Invest in Kids working paper no. 7 [Internet]. Washington (DC): 2005 [cited 2014 May 2]. Available from wvpartners.org/docs/report_ ivk_gomby_2005.pdf

13. Howard KS, Brooks-Gunn J. The role of home-visiting programs in preventing child abuse and neglect. Future Child. 2009;19(2) $119-46$.

14. Nurse-Family Partnership. Implementation overview \& planning: a guide for prospective Nurse-Family Partnership implementing agencies [Internet]. Denver (CO): Nurse-Family Partnership; 2010 [cited 2014 May 2]. Available from: http://www.nursefamilypartnership. org/assets/PDF/Policy/HV-Funding-Guidance/ NFP_Overview_Planning

15. Nurse-Family Partnership. Pregnancy assistances for first-time moms [Internet]. Denver (CO): Nurse-Family Partnership; 2011 [cited 2014 Jun 15]. Available from: http:// www.nursefamilypartnership.org/first-timemoms

16. Hicks D, Larson C, Nelson C, Olds DL, Johnston $\mathrm{E}$. The influence of collaboration on program outcomes: The Colorado Nurse-Family Partnership. Eval Rev. 2008;32(5):453-77.

17. Daro D. Home visitation: assessing progress, managing expectations [Internet]. Chicago (IL): Ounce of Prevention Fund: 2006 [cited 2014 May 2]. Joint publication of the Chapin Hall Center for Children. Available from: http://www.chapinhall. org/sites/default/files/old_reports/323.pdf
18. Daro D, Cohn-Donnelly A, editors. Child abuse prevention: accomplishments and challenges. APSAC handbook on child maltreatment. $2^{\text {nd }}$ ed. Newbury Park (CA): SAGE Publications; 2001.

19. Schumacher R, Hamm K, Goldstein A, Lonbardi J. Starting off right: promoting child development from birth in state early care and education initiatives [Internet]. Washington (DC): Centre for Law and Social Policy; 2006 [cited 2014 May 2]. Available from: http://www.clasp.org/publications/ startingoffright.html

20. Council on Child and Adolescent Health. The role of home-visitation programs in improving health outcomes for children and families. Pediatrics. 1998;123(2):486-9.

21. Jack SM, Busser D, Sheehan D, Gonzalez A, Zwygers EJ, MacMillan HL. Adaptation and implementation of the Nurse-Family Partnership in Canada. Can J Public Health. 2012;103(7):eS42-8.

22. Jack SM, MacMillan HL. Adaptation and evaluation of the Nurse-Family Partnership in Canada [Internet]. The Hague (ND): Early Childhood Matters; 2014 [cited 2014 Jun 15]. Available from: http://earlychildhood magazine.org/adaptation-and-evaluation-ofthe-nurse-family-partnership-in-canada/

23. Dmytryshyn AL, Jack SM, Ballantyne M, Wahoush O, MacMillan HL. Long-term home visiting with vulnerable young mothers: an interpretive description of the impact on public health nurses. BMC Nursing. 2015;14:12. doi:10.1186/s12912015-0061-2.

24. Landy CK, Jack SM, Wahoush O, Sheehan D. MacMillan HL; NFP Hamilton Research Team. Mothers' experiences in the NurseFamily Partnership program: A qualitative case study. BMC Nursing. 2012;11:15. doi:10.1186/1472-6955-11-15.

25. Rew L, Koniak-Griffin D, Lewis MA, Miles M, O'Sullivan A. Secondary data analysis: new perspective for adolescent research. Nurs Outlook.2000;48(5):223-9.

26. NVivo qualitative data analysis software, version 10. Doncaster (VC): QSR International Pty Ltd; 2013.

27. Hsieh HF, Shannon SE. Three approaches to qualitative content analysis. Qual Health Res. 2005;15(9):1277-88.
28. Lincoln YS, Guba EG. Naturalistic inquiry. Newbury Park (CA): SAGE Publications; 2005.

29. Child and Family Services Act, RSO 1990, c C.11 [Internet]. Available from: http:// canlii.ca/t/ldxd

30. Landy CK, Jack SM, Wahoush O, Sheehan D, MacMillan HL. NFP Hamilton Research Team. Mothers' experiences in the NurseFamily Partnership program: A qualitative case study. BMC Nurs. 2012;11:15.

31. Peterson N. Interagency collaboration under Part $\mathrm{H}$ : the key to comprehensive, multidisciplinary, coordinated infant/toddler intervention. J Early Interv. 2003;15(1):89-105.

32. Foster-Fishman PG, Salem DA, Allen NA, Fahrbach K. Facilitating interorganizational collaboration: the contributions of interorganizational alliances. Am J Community Psychol. 2001;29(6):875-905.

33. Trotter G. Family Nurse Partnership programme in Scotland: an update [Internet]. Community Pract. 2012 [cited 2014 Jun 15]. Available from: http://www.readperiodicals. com/201208/2731312821.html 